\title{
The effects of an invasive seaweed on native communities vary along a gradient of land-based human impacts
}

Fabio Bulleri, Fabio Badalamenti, Ljiljana Iveša, Barbara Mikac, Luigi Musco, Andrej Jaklin, Alex Rattray, Tomás T Vega Fernández, Lisandro Benedetti-Cecchi

The difficulty in teasing apart the effects of biological invasions from those of other anthropogenic perturbations has hampered our understanding of the mechanisms underpinning the global biodiversity crisis. The recent elaboration of global-scale maps of cumulative human impacts provides a unique opportunity to assess how the impact of invaders varies among areas exposed to different anthropogenic activities. A recent metaanalysis has shown that the effects of invasive seaweeds on native biota tend to be more negative in relatively pristine than in human impacted environments. Here, we tested this hypothesis through the experimental removal of the invasive green seaweed, Caulerpa cylindracea, from rocky reefs across the Mediterranean Sea. More specifically, we assessed which out of land-based and sea-based cumulative impact scores was a better predictor of the direction and magnitude of the effects of this seaweed on extant and recovering native assemblages. Approximately 15 months after the start of the experiment, the removal of C. cylindracea from extant assemblages enhanced the cover of canopy-forming macroalgae at relatively pristine sites. This did not, however, result in major changes in total cover or species richness of native assemblages. Preventing C. cylindracea reinvasion of cleared plots at pristine sites promoted the recovery of canopy-forming and encrusting macroalgae and hampered that of algal turfs, ultimately resulting in increased species richness. These effects weakened progressively with increasing levels of landbased human impacts and, indeed, shifted in sign at the upper end of the gradient investigated. Thus, at sites exposed to intense disturbance from land-based human activities, the removal of $\mathrm{C}$. cylindracea fostered the cover of algal turfs and decreased that of encrusting algae, with no net effect on species richness. Our results suggests that competition from C. cylindracea is an important determinant of benthic assemblage diversity in pristine environments, but less so in species-poor assemblages found at sites exposed to intense disturbance from land-based human activities, where either adverse physical factors or lack of propagules may constrain the number of potential native colonizers. Implementing measures to reduce the establishment and spread of $\mathrm{C}$. cylindracea in areas little impacted by land-based human activities should be considered a priority for preserving the biodiversity of Mediterranean shallow rocky reefs. 
1

2

3

4

$5 \quad$ Fabio Bulleri ${ }^{*}$, Fabio Badalamenti ${ }^{2}$, Ljiljana Iveša $^{3}$, Barbara Mikac $^{2}$, Luigi Musco $^{2}$, Andrej

7

8

9

10

11

12

13

14

15

16

$17 *$ Corresponding author

18 Email: fabio.bulleri@unipi.it

\section{THE EFFECTS OF AN INVASIVE SEAWEED ON NATIVE COMMUNITIES VARY \\ ALONG A GRADIENT OF LAND-BASED HUMAN IMPACTS}

${ }^{1}$ Dipartimento di Biologia, Università di Pisa, Via Derna 1, 56126, Pisa, Italy

${ }^{2}$ CNR-IAMC, Istituto per l'Ambiente Marino Costiero, Castellammare del Golfo, Italy

${ }^{3}$ Ruđer Bošković Institute, Center for Marine Research, G. Paliaga 5, 52210 Rovinj, Croatia 


\section{ABSTRACT}

22

The difficulty in teasing apart the effects of biological invasions from those of other anthropogenic perturbations has hampered our understanding of the mechanisms underpinning the global biodiversity crisis. The recent elaboration of global-scale maps of cumulative human impacts provides a unique opportunity to assess how the impact of invaders varies among areas exposed to different anthropogenic activities. A recent meta-analysis has shown that the effects of invasive seaweeds on native biota tend to be more negative in relatively pristine than in human impacted environments. Here, we tested this hypothesis through the experimental removal of the invasive green seaweed, Caulerpa cylindracea, from rocky reefs across the Mediterranean Sea. More specifically, we assessed which out of land-based and sea-based cumulative impact scores was a better predictor of the direction and magnitude of the effects of this seaweed on extant and recovering native assemblages. Approximately 15 months after the start of the experiment, the removal of C. cylindracea from extant assemblages enhanced the cover of canopy-forming macroalgae at relatively pristine sites. This did not, however, result in major changes in total cover or species richness of native assemblages. Preventing $C$.

cylindracea re-invasion of cleared plots at pristine sites promoted the recovery of canopyforming and encrusting macroalgae and hampered that of algal turfs, ultimately resulting in increased species richness. These effects weakened progressively with increasing levels of landbased human impacts and, indeed, shifted in sign at the upper end of the gradient investigated. Thus, at sites exposed to intense disturbance from land-based human activities, the removal of $C$. cylindracea fostered the cover of algal turfs and decreased that of encrusting algae, with no net 
42 effect on species richness. Our results suggests that competition from C. cylindracea is an

43 important determinant of benthic assemblage diversity in pristine environments, but less so in

44 species-poor assemblages found at sites exposed to intense disturbance from land-based human

45 activities, where either adverse physical factors or lack of propagules may constrain the number

46 of potential native colonizers. Implementing measures to reduce the establishment and spread of

47 C. cylindracea in areas little impacted by land-based human activities should be considered a

48 priority for preserving the biodiversity of Mediterranean shallow rocky reefs. 


\section{INTRODUCTION}

Concerns over the potential of invasive species to alter biodiversity, impair ecosystem functioning and cause economic loss has stimulated research on the mechanisms underpinning variations in their impacts on native species and communities (Mack et al., 2000). Although a unified framework for predicting the direction and magnitude of invaders' impacts is still elusive, some generalities have started to emerge from qualitative and quantitative synthesis of the literature (Schaffelke \& Hewitt, 2007; Williams \& Smith, 2007; Gaertner et al., 2009; Thomsen et al., 2009, 2014; Powell et al., 2011, Vilà et al., 2011; Maggi et al., 2015; Tamburello et al., 2015). For instance, the effects of non-native plants on native plant communities have been found to be generally negative, whilst those on higher trophic-level communities or species can be less predictable, varying from negative to positive (Vilà et al., 2011; Thomsen et al., 2014; Maggi et al., 2015).

More recently, Tamburello et al. (2015) have shown, by means of a global meta-analysis, that the effects of non-native seaweeds on native benthic communities tend to shift from negative to neutral or positive along a gradient of increasing cumulative human impact (Halpern et al., 2008), suggesting that the severity of their effects might be greater in relatively pristine than in degraded environments. The impact score developed by Halpern et al. (2008), combines a diverse set of anthropogenic drivers, including climate change, land-based and sea-based human impact. Nonetheless, it provides little insight into the nature of the key drivers underpinning variations in the effects of non-native seaweeds on native benthic assemblages. Land-based human impacts, such as inorganic pollution, enhanced nutrient loading and sedimentation have been widely shown to cause changes in the structure (i.e., species composition and relative abundance) of benthic assemblages on temperate rocky reefs (Benedetti-Cecchi et al., 2001; 
73 Airoldi \& Beck, 2007; Gorman et al., 2009). Thus, it could be argued that land-based human

74 impacts are more likely to influence the fitness and competitive ability of both native and non-

75 native macroalgal species, as well as the outcome of their interactions, in comparison to sea-

76 based impacts.

77

78

79

80

81

82

83

84

85

86

87

88

89

90

91

92

93

94 higher scores of cumulative human impacts.

Here, we experimentally assessed how the effects of the invasive seaweed, C. cylindracea Sonder, vary among Mediterranean rocky reefs exposed to different levels of human impact. This seaweed, introduced in the NW Mediterranean about 20 years ago, has the potential to reduce the abundance of encrusting, turf-forming and erect macroalgae, ultimately decreasing species richness, total cover and spatial variability of native assemblages (Piazzi et al., 2001; Bulleri et al., 2010; Gennaro \& Piazzi, 2011; Papini et a., 2013; Tamburello et al., 2015). Assessing the relative role of land-based (i.e. coastal human population, discharge of fertilizers and pesticides, river run-off and risk of hypoxia) versus sea-based (i.e. shipping activities, oil spill risk and fishing activities) human impacts in regulating the direction and intensity of the effects of C. cylindracea on native assemblages is, however, key for prioritizing areas of management and invader control strategies.

We expected that the severity of land-based cumulative human impacts would be a better predictor than sea-based impacts of variations in the effects of $C$. cylindracea on the abundance of main morphological groups of benthic organisms and on the total cover and diversity of native assemblages. According to the findings of Tamburello et al. (2015), we predicted the effects of C. cylindracea on native morphological group abundance and community structure to be negative in relatively pristine areas and become neutral or positive in areas characterized by 
Due to the alteration of internal feed-back mechanisms, the changes caused by invasive

96

97 species can be difficult to revert (Gaertener et al., 2014). For instance, enhanced sediment deposition in the presence of C. cylindracea (Piazzi et al., 2007) can lock the system into an "invaded" state characterized by the dominance of algal turfs (Bulleri et al., 2010). The removal of the invader and of the assemblages established under its dominance is, therefore, a crucial requirement of experimental tests of the impacts of biological invasions (Bulleri et al., 2010). For this reason, we predicted that that preventing re-invasion by C. cylindracea of areas totally cleared at the beginning of the experiment would generate greater changes than the removal of C. cylindracea from extant assemblages.

\section{MATERIALS AND METHODS}

This study was carried out at 8 sites in the Mediterranean Sea (Fig. 1). Due to logistic constraints, study sites were not evenly distributed across the Mediterranean. Nonetheless, in order to encompass a wide gradient of human impacts, they were haphazardly chosen in the proximity of major urban or industrial centers, extra-urban sites, and along the coast of islands little exposed to human activities. At each site, twenty 40 x $40 \mathrm{~cm}$ plots were marked with epoxy putty (Veneziani S subcoat) at a depth of 5-8 m, in June 2012. Five plots were randomly assigned to each of the following four treatments generated by crossing disturbance ( 2 levels; control versus clearing of the whole assemblage, hereafter referred to as extant and recovering assemblages, respectively) and manipulation of $C$. cylindracea (2 levels; present versus removed): 1) removal of $C$. cylindracea from extant assemblages, 2) total clearing of extant assemblages preventing the re-invasion by C. cylindracea, 3) total clearing of extant assemblages but allowing re-invasion by $C$. cylindracea and 4) controls, assemblages invaded by $C$. cylindracea. Clearing of extant assemblages (treatments 2 and 3), consisting in the removal of 
118 erect organisms by means of a metal brush, was carried out once at the beginning of the study.

119 Experimental conditions were maintained by manually removing C. cylindracea every 2-4

120 weeks. During visits in the field, the percentage cover of $C$. cylindracea was assessed in the

121 central $20 \times 20 \mathrm{~cm}$ area of each plot (to avoid edge effects), using a grid subdivided in 25

122 quadrats. A score from 0 to $4 \%$ was given to each sub-quadrat and the percentage cover was

123 obtained by summing over the entire set of subquadrats. Although the natural cover of $C$.

124 cylindracea varied among study sites, experimental conditions were maintained throughout the

125 study period (Fig. 2). After $\sim 15$ months from the start of the experiment, the cover of

126 macroalgae and sessile invertebrates was estimated by means of the same visual technique used

127 to estimate that of C. cylindracea. Organisms were generally identified to the species level,

128 except for encrusting coralline and filamentous algae. For analysis, macroalgal species were

129 included into three major morphological groups: encrusting, turf-forming and canopy-forming

130 (Airoldi et al., 1995; Benedetti-Cecchi et al., 2001). Likewise, sessile invertebrates such as

131 sponges, ascidians, bryozoans, hydrozoans, bivalves, tubiculous molluscs and polychaetes were

132 analyzed as a single morphological group. Except from the filamentous macroalga,

133 Womersleyella setacea, present in two plots at Site 4, species composing benthic assemblages

134 were native. Fieldwork along the Italian coast has been conducted with permits from Comune di

135 Livorno (Prot. N 71719), Ente Parco Arcipelago Toscano (Prot. N. 1797) and Area Marina

136 Protetta Plemmirio (CNR-IAMC- Consorzio Plemmirio convention № 0007139). Fieldwork

137 along the Croatian coast has been conducted with permits from the Ministry of Culture (UP/I-

138 612-07/11-33/1015; 532-08-01-01/1-11-04; from 25 October 2011).

139 For each study site, using ArcGIS 10.1, we extracted a set of both land-based and sea-

140 based anthropogenic drivers from the georeferenced layers developed by Micheli et al. (2013) for 
141 the Mediterranean basin. Land-based drivers included coastal population density, nutrient input

142 (fertilizers), organic pollution (pesticides), urban run-off and risk of hypoxia, whilst sea-based

143 drivers included benthic structures (oil rigs), commercial shipping, invasive species, artisanal

144 fishing, oil spills and 5 different types of commercial fishing (see Table S1 in Micheli et al.

145 2013). These drivers were included to take into account the potential human effects, either direct

146 or indirect, on benthic habitats. Invasive species were included among the sea-based drivers

147 since the importance of competitive effects of C. cylindracea on native assemblages can be

148 hypothesized to be less severe in communities altered by the presence of multiple introduced

149 species (Tamburello et al., 2015). Following Micheli et al. (2013), we log (x+1)-transformed and

150 rescaled each driver layer between $0-1$ to render them in a single, unitless scale that allows for

151 direct comparison.

152 Both land- and sea-based cumulative impact scores at the northernmost (Vrsar) and

153 southernmost (Plemmirio) sites were within the range found within the study sites in the

154 Northern Thyrrenian and Ligurian Seas (i.e. they did not constitute extremes). When considering

155 land-based human impacts, sites with higher scores were clumped along the mainland coast of

156 Tuscany (Site 5 to 8; Fig. 1, 2). By contrast, sites were rather well interspersed across the basin

157 in terms of sea-based and total cumulative human impact scores (Fig. 2). Differences among sites

158 other than those due to local human influences (e.g., climate, oceanography, latitude), were,

159 however, accounted for by the statistical analyses (see below).

160 The effects of C. cylindracea on the percentage cover of morphological groups, on the total

161 cover and species richness of native assemblages were analyzed, separately for extant and

162 recovering assemblages, by means of linear mixed-effect models (Zuur et al., 2009). The

163 experimental removal of the invader (C. cylindracea removed vs $C$. cylindracea present), 
164 cumulative sea-based and land-based human impact scores and their interaction with the $C$.

165 cylindracea treatment were treated as fixed factors. The site was included in the analyses as a

166 random factor, in order to formally assess any potential bias due to unmeasured factors (not

167 related to human impacts) varying among sites. Assumptions of linearity and homogeneity of

168 variances were checked through inspection of plots of residuals vs. fitted values and quantile-

169 quantile plots. Log transformation of total cover values was effective in improving linearity.

170 Canopy-forming species, belonging to the genera Cystoseira and Sargassum, were present

171 only at three locations (i.e. 1, 2 and 4), preventing a test of variations in the effects of $C$.

172 cylindracea on these algal forms along human impact gradients. The effects of $C$. cylindracea on

173 canopy-formers were therefore simply tested by means of a 3-way ANOVA, including the

174 factors $C$. cylindracea treatment (present versus removed; fixed), assemblage (extant versus

175 cleared; fixed) and site (random, with 3 levels). All analyses were done in R 3.2.3 (R

176 Development Core Team, 2013) using the libraries lme4 and lmerTest and GAD.

177

178

179

180

181

182

183

184

185

186

\section{RESULTS}

The removal of $C$. cylindracea had no effect on the cover of encrusting and turf-forming algae and sessile invertebrates (Table 1A), as well as on the total cover and species richness of extant benthic assemblages, (Table 1B). The cover of sessile invertebrates and species richness decreased at increasing levels of land-based impacts (Table 1A, B; Fig. 3A, B) whilst the total cover of extant assemblages declined significantly with increasing levels of human sea-based impacts (Table 1B; Fig. 3C).

The effects of the removal of $C$. cylindracea on the cover of encrusting macroalgae in recovering plots shifted from positive at the most pristine sites to negative at those more 
187 impacted by land-based human activities (Fig. 4A). By contrast, the effects of the removal of $C$.

188 cylindracea on algal turf cover were negative at the site least impacted by land-based activities,

189 but became increasingly positive towards the upper end of the human disturbance gradient

190 investigated (Table 2A, Fig. 4B). The cover of sessile invertebrates in recovering plots was not

191 affect by the removal of C. cylindracea but decreased with increasing levels of land-based

192 impacts (Table 2A, Fig. 4C). Finally, the cover of canopy-forming macroalgae was greater in

193 plots from which C. cylindracea was removed (mean $\pm \mathrm{SE}=18.9 \pm 4.41)$ than in those in which

194 it was left untouched (mean $\pm \mathrm{SE}=9.68 \pm 2.83$ ), consistently among study sites and between

195 control and cleared plots (Table S2).

196 The total cover of recovering assemblages was not affected by the removal of $C$.

197 cylindracea and did not show any significant relationship with either land-based or sea-based

198 human impacts (Table 2B). By contrast, the effects of removing C. cylindracea on species

199 richness in cleared plots varied according to the intensity of land-based human impacts (Table

200 2B). The removal of C. cylindracea caused a marked increase in species richness at relatively

201 pristine sites, with a trend for this positive effect to weaken when moving towards more

202 impacted areas and, indeed, to shift to negative towards the upper end of impact gradient

203 analyzed (Fig. 4D). In particular, removing $C$. cylindracea at the most pristine site caused an

204 increase in species richness of about 14\%. In order to assess whether this pattern was driven by

205 the particularly high species richness in one single C. cylindracea removal plot (species richness

$206=24)$ at the least impacted study site (Fig. 4D), the analysis was repeated after the exclusion of

207 this potential outlier. The interaction between C. cylindracea treatment of land-based human

208 impact resulted significant also in this analysis (Table S1). 


\section{DISCUSSION}

211 The seaweed, Caulerpa cylindracea, with a distribution spanning $\sim 10^{\circ}$ of latitude and

212 more than $\sim 30^{\circ}$ of longitude, is one the most successful invaders in the Mediterranean (Verlaque

213 et al., 2004; Piazzi et al., 2005; Bulleri et al., 2011). The removal of this seaweed from extant

214 assemblages had positive effects on canopy-forming species at sites little exposed to human

215 activities, where these algal forms were found (i.e. sites 1, 2 and 4). Canopy stands can provide

216 habitat for a variety of understorey species, including sessile invertebrates and encrusting

217 species, which can be rapidly swamped by fast-growing algal turfs in full light conditions

218 (Benedetti-Cecchi et al., 2001, Bulleri et al., 2002). Here, the increase in the cover of canopy-

219 forming macroalgae elicited by the removal of C. cylindracea may have been too small to foster

220 the recovery of understorey species and, hence, to influence community properties, such as total

221 cover or species richness.

222 Invasive species can trigger regime shifts, thus generating changes that can be difficult to

223 reverse simply through the removal of the invader (Gaertner et al., 2014). Previous experimental

224 work has indeed shown that the removal of $C$. cylindracea alone was little effective in promoting

225 the recovery of architecturally complex macroalgal species (Bulleri et al., 2010). Here, the

226 removal of C. cylindracea and that of the assemblages that developed under its dominance, likely

227 reinstating more favorable environmental conditions, caused marked changes to native

228 assemblages which varied according to the severity of land-based human impacts.

229 At pristine sites, preventing re-invasion of cleared plot by C. cylindracea favoured the

230 recovery of canopy-forming and encrusting macroalgae, whilst it depressed that of algal turfs,

231 ultimately increasing species richness. C. cylindracea is likely to enhance the competitive ability

232 of algal turfs in respect to other components of native assemblages, such as canopy-forming and 
233 encrusting macroalgae, through the alteration of abiotic conditions (e.g. enhanced trapping of

234 sediments; Piazzi et al., 2007). Our results suggest that altered abiotic conditions persisted,

235 however, beyond the removal of the invader and significant changes at the community level can

236 emerged only after legacy effects of invasion were disrupted by an intense disturbance event

237 (i.e., clearing of extant assemblages).

238 In contrast, at more impacted sites, algal turfs responded positively to the removal of $C$.

239 cylindracea. Thus, the effects of C. cylindracea on algal turfs shifted from positive at pristine

240 sites to negative at degraded sites. Turfs are, in fact, generally dominant along urbanized

241 temperate coasts worldwide, where stronger competitors have declined as a consequence of

242 human alteration of abiotic conditions (Gorman et al., 2009, Bulleri et al., submitted). Under

243 these circumstances, algal turfs do not rely on C. cylindracea to reduce competition pressure

244 from native species and competitive effects from the invader prevail.

245 Seminal work by Connell (1961) has shown that community regulation by competitive

246 interactions is more likely under relatively benign environmental conditions. A diminished role

247 of competition at increasing levels of environmental stress, as postulated by the Stress Gradient

248 Hypothesis (Bertness \& Callaway, 1994), has been documented across a variety of terrestrial

249 systems (Grime, 1974; Huckle et al., 2002). In this light, the presence of C. cylindracea would

250 reduce the number of species in native communities which assembly is mostly structured by

251 competition, whereas it would have little effect on urban or extra-urban reefs, where filtering by

252 adverse physical conditions limits native species richness (e.g. dominance by filamentous algal

253 turfs; Tamburello et al., 2012, 2015).

254 Alternatively, the weak response of assemblages to the removal of C. cylindracea and to

255 the provision of free space (through the clearing of plots) at more impacted sites could be due to 
256 the unavailability of propagules of potential native colonizers other than those already well

257 established locally. Very low species diversity at these sites suggests, in fact, that local

258 assemblages were composed of a few tolerant turf-forming species. Low propagule availability

259 of native species has been shown to hamper restoration both in terrestrial and aquatic

260 environments (Hansson et al., 1998; Prober et al., 2009). By contrast, at more pristine sites, the

261 removal of C. cylindracea, in combination with the provision of free space, may have created the

262 opportunity for rarer species within the local pool to expand their distribution.

263 The cover of C. cylindracea largely varied among study sites, without any apparent

264 relationship with the intensity of either land- or sea-based human impact scores. Removing $C$.

265 cylindracea generated more positive effects at pristine sites (e.g. Capraia and Elba Islands)

266 despite its relatively low cover. By contrast, it had weak effects at more impacted sites, where its

267 cover in re-invaded cleared plots varied by one order of magnitude (between $\sim 80 \%$ at Vrsar and

$268 \sim 4 \%$ at Quercianella). The effects of C. cylindracea on native species richness were, thus,

269 largely independent from its abundance. Previous studies have found that low cover of this

270 seaweed can cause alterations in native macroalgal assemblages (Bulleri et al., 2010). Our

271 findings suggest that features of native assemblages (e.g. species composition and relative

272 abundance) were more important than the abundance of $C$. cylindracea in determining the extent

273 of its effects on the native biota. There is mounting evidence that the effects of aquatic invasive

274 species on the native biota may be density-dependent (Thomsen et al., 2011; Gribben et al.,

275 2013). Density-dependence in the effects of invasive seaweeds might be, however, community-

276 specific. Being modulated by the features of the recipient community, the intensity of the effects

277 of an invader may not scale with its abundance consistently across communities that largely vary

278 in species identity and relative abundance. 
predictors of changes in total cover and species richness of extant and recovering assemblages.

In particular, the total cover declined along the sea-based human impact score, whilst the cover

of encrusting algae and sessile invertebrate and species richness declined along the land-based

of natural communities. Sea-based activities, such as fisheries and shipping activities seem to limit community productivity; mechanical damage due to trawling, operation of gillnets or anchoring, associated with degradation of environmental conditions due to pulse perturbations such as oil spills and ballast water release, may reduce the overall productivity of benthic assemblages, without causing major alterations in species richness. Land-based human impacts, such as inorganic pollution, water turbidity, enhanced nutrient loading and sedimentation would, by contrast, reduce the abundance and number of sessile species able to thrive on shallow rocky reefs (Benedetti-Cecchi et al., 2001; Airoldi \& Beck, 2007; Gorman et al., 2009). Decreased species richness is not necessarily associated with decreases in total cover, as compensation mechanisms among species characterized by different susceptibility to environment stress can sustain the standing biomass (Ernest \& Brown, 2001). Tamburello et al. (2015) and suggests that the effects of invasive seaweeds are likely to be more negative at relatively well preserved sites. In addition, it suggests that land-based human impacts might be a better predictor of invaders' effects in respect to sea-based impacts. Encompassing a wider human impact gradient and assessing variation among sites assigned a similar impact score will be crucial to gain conclusive evidence of the sign and strength of the relationship between the severity of human impacts and the effects of invasive seaweeds on the native biota. 
302 Nonetheless, following a precautionary principle, implementing the control of those activities

303 (e.g. recreational boating, aquaculture) that can favor the spread of invasive seaweeds into 304 relatively pristine environments could be considered strategic to preserve the biodiversity of 305 temperate shallow rocky reefs.

\section{ACKNOWLEDGEMENTS}

307 We thank G. Bellistri, C. Ravaglioli, G. Ghedini and L. Tamburello for help with fieldwork and 308 C. Ravaglioli, M. Dal Bello and two anonymous reviewers for commenting on earlier ms drafts. 309 We also thank Rosaria Rizza (Director of Consorzio Plemmirio MPA) and her staff (E. Di

310 Pietro, G. Mazza, M. Moschella e L. Pasolli) for helpful assistance provided during the study. 
311

312

313

314

315

316

317

318

319

320

321

322

323

324

325

326

327

328

329

330

331

332

\section{REFERENCES}

Airoldi L., Beck M.W. 2007. Loss, status and trends for coastal marine habitats of Europe. In Oceanography and Marine Biology 45: 345-405.

Airoldi L., Rindi F., Cinelli F. 1995. Structure, seasonal dynamics and reproductive phenology of a filamentous turf assemblage on a sediment influenced, rocky subtidal shore. Botanica Marina 38:227-238

Williams S.L., Smith J.E. 2007. A global review of the distribution, taxonomy, and impacts of introduced seaweeds. Annual Review of Ecology Evolution and Systematics 38:327-359.

Benedetti-Cecchi L., Pannacciulli F., Bulleri F., Moschella P.S., Airoldi L., Relini G., Cinelli F. 2001. Predicting the consequences of anthropogenic disturbance: large-scale effects of loss of canopy algae on rocky shores. Marine Ecology Progress Series 214: 137-150 (doi:10.3354/meps214137).

Bertness M.D., Callaway R. 1994 Positive interactions in communities. Trends in Ecology \& Evolution 9:191-193 (doi:10.1016/0169-5347(94)90088-4).

Bulleri F., Alestra T., Ceccherelli G., Tamburello L., Pinna S., Sechi N., Benedetti-Cecchi L. 2011. Determinants of Caulerpa racemosa distribution in the north-western Mediterranean. Marine Ecology Progress Series 431:55-67.

Bulleri F., Balata D., Bertocci I., Tamburello L., Benedetti-Cecchi L. 2010. The seaweed Caulerpa racemosa on Mediterranean rocky reefs: from passenger to driver of ecological change. Ecology 91:2205-2212 (doi:10.1890/09-1857.1).

Bulleri F., Benedetti-Cecchi L., Acunto S., Cinelli F., Hawkins S.J. 2002. The influence of canopy algae on vertical patterns of distribution of low-shore assemblages on rocky coasts 
in the northwest Mediterranean. Journal of Experimental Marine Biology and Ecology 267:89-106.

Bulleri F., Cucco A., Dal Bello M., Maggi E., Ravaglioli C., Benedetti-Cecchi L. submitted The role of wave-exposure and human impacts in regulating the distribution of alternative habitats on NW Mediterranean rocky reefs. Estuarine Coastal and Shelf Science.

Connell J.H. 1961. The influence of interspecific competition and other factors on the distribution of the barnacle Chthamalus Stellatus. Ecology 42:710-723.

Ernest S.K.M., Brown J.H. 2001. Homeostasis and compensation: The role of species and resources in ecosystem stability. Ecology 82:2118-2132 (doi:10.2307/2680220).

Gaertner M., Biggs R., Te Beest M., Hui C., Molofsky J., Richardson D.M. 2014. Invasive plants as drivers of regime shifts: identifying high-priority invaders that alter feedback relationships. Diversity and Distributions 20:733-744 (doi:10.1111/ddi.12182).

Gaertner M., Den Breeyen A., Hui C., Richardson D.M. 2009. Impacts of alien plant invasions on species richness in Mediterranean-type ecosystems: a meta-analysis. Progress in Physical Geography 33: 319-338 (doi:10.1177/0309133309341607).

Gennaro P., Piazzi L. 2011. Synergism between two anthropic impacts: Caulerpa racemosa var. cylindracea invasion and seawater nutrient enrichment. Marine Ecology Progress Series 427:59-70.

Gorman D., Russell B.D., Connell S.D. 2009. Land-to-sea connectivity: linking human-derived terrestrial subsidies to subtidal habitat change on open rocky coasts. Ecological Applications 19:1114-1126 (doi:10.1890/08-0831.1). 
354 Gribben P.E., Byers J.E., Wright J.T., Glasby T.M. 2013. Positive versus negative effects of an 355 invasive ecosystem engineer on different components of a marine ecosystem. Oikos 122: 816-824 (doi:10.1111/j.1600-0706.2012.20868.x).

357

358

Grime J.P. 1974. Vegetation classification by reference to strategies. Nature 250: 26-31. (doi:10.1038/250026a0).

Halpern B.S., Walbridge S., Selkoe K.A., Kappel C.V., Micheli F., D'Agrosa C., Bruno J.F., Casey K.S., Ebert C., Fox H.E., et al. 2008. A global map of human impact on marine ecosystems. Science 319:948-952 (doi:10.1126/science.1149345).

Hansson L.A., Annadotter H., Bergman E., Hamrin S.F., Jeppesen E., Kairesalo T., Luokkanen E., Nilsson P.A., Sondergaard M., Strand J. 1998. Biomanipulation as an application of food-chain theory: Constraints, synthesis, and recommendations for temperate lakes. Ecosystems 1:558-574 (doi:10.1007/s100219900051).

Huckle J.M., Marrs R.H., Potter J.A. 2002. Interspecific and intraspecific interactions between salt marsh plants: integrating the effects of environmental factors and density on plant performance. Oikos 96:307-319 (doi:10.1034/j.1600-0706.2002.960213.x).

Mack R.N., Simberloff D., Lonsdale W.M., Evans H., Clout M., Bazzaz F.A. 2000. Biotic invasions: Causes, epidemiology, global consequences, and control. Ecological Applications 10: 689-710 (doi:10.2307/2641039).

Maggi E., Benedetti-Cecchi L., Castelli A., Chatzinikolaou E., Crowe T.P., Ghedini G., Kotta J., Lyons D.A., Ravaglioli C., Rilov G., et al. 2015. Ecological impacts of invading seaweeds: a meta-analysis of their effects at different trophic levels. Diversity and Distributions 21:112. (doi:10.1111/ddi.12264). 
376 Micheli F., Halpern B.S., Walbridge S., Ciriaco S., Ferretti F., Fraschetti S., Lewison R., Nykjaer

377 L., Rosenberg A.A. 2013. Cumulative human impacts on Mediterranean and Black Sea

378 marine ecosystems: Assessing current pressures and opportunities. Plos One 8(12)

379 (doi:e7988910.1371/journal.pone.0079889).

380 Papini A., Mosti S., Santosuosso U. 2013. Tracking the origin of the invading Caulerpa

381 (Caulerpales, Chlorophyta) with Geo $\neg$ graphic Profiling, a criminological technique for a killer alga. Biological Invasions 15:1613-1621.

383

384

385

386

387

388

389

390

391

392

393

394

395

396

397

Piazzi L., Balata D., Foresi L., Cristaudo C., Cinelli F. 2007. Sediment as a constituent of Mediterranean benthic communities dominated by Caulerpa racemosa var cylindracea. Scientia Marina 71:129-135.

Piazzi L., Ceccherelli G., Cinelli F. 2001. Threat to macroalgal diversity: effects of the introduced green alga Caulerpa racemosa in the Mediterranean. Marine Ecology Progress Series 210: 149-159 (doi:10.3354/meps210149).

Piazzi L., Meinesz A., Verlaque M., Akcali B., Antolic B., Argyrou M., Balata D., Ballesteros E., Calvo S., Cinelli F., et al. 2005. Invasion of Caulerpa racemosa var. cylindracea (Caulerpales, Chlorophyta) in the Mediterranean Sea: an assessment of the spread. Cryptogamie Algologie 26:189-202.

Powell K.I., Chase J.M., Knight T.M. 2011 A synthesis of plant invasion effects on biodiversity across spatial scales. American Journal of Botany 98:539-548. (doi:10.3732/ajb.1000402).

Prober S., Taylor S., Edwards R., Mills B. 2009. Effectiveness of repeated autumn and spring fires for understorey restoration in weed-invaded temperate eucalypt woodlands. Applied Vegetation Science 12:440-450. 
398 R Development Core Team (2013) The R project for statistical computing, version 2.15. R $399 \quad$ Foundation for Statistical Computing,Vienna, Austria.

400 Schaffelke B., Hewitt C.L. 2007. Impacts of introduced seaweeds. Botanica Marina 50: 397-417 $401 \quad$ (doi:10.1515/bot.2007.044).

402 Tamburello L., Benedetti-Cecchi L., Ghedini G., Alestra T., Bulleri F. 2012. Variation in the 403 structure of subtidal landscapes in the NW Mediterranean Sea. Marine Ecology Progress 404 Series 457:29-41 (doi:10.3354/meps09703).

405

406

407

408

409

410

411

412

413

414

415

416

417

418

419

Tamburello L., Maggi E., Benedetti-Cecchi L., Bellistri G., Rattray A.J., Ravaglioli C., Rindi L., Roberts J., Bulleri F. 2015. Variation in the impact of non-native seaweeds along gradients of habitat degradation: a meta-analysis and an experimental test. Oikos 124: 1121-1131 (doi:10.1111/oik.02197).

Thomsen M.S., Byers J.E., Schiel D.R., Bruno J.F., Olden J.D., Wernberg T., Silliman B.R. 2014. Impacts of marine invaders on biodiversity depend on trophic position and functional similarity. Marine Ecology Progress Series 495:39-47 (doi:10.3354/meps10566).

Thomsen M.S., Olden J.D., Wernberg T., Griffin J.N., Silliman B.R. 2011. A broad framework to organize and compare ecological invasion impacts. Environmental Research 111:899 908.

Thomsen M.S., Wernberg T., Tuya F., Silliman B.R. 2009. Evidence for impacts of nonindigenous macroalgae: A meta-analysis of experimental field studies. Journal of Phycology 45:812-819 (doi:10.1111/j.1529-8817.2009.00709.x).

Verlaque M., Afonso-Carrillo J., Gil-Rodriguez M.C., Durand C., Boudouresque C.F., Le Parco Y. 2004. Blitzkrieg in a marine invasion: Caulerpa racemosa var. cylindracea 
420 (Bryopsidales, Chlorophyta) reaches the Canary Islands (north-east Atlantic). Biological Invasions 6:269-281 (doi:10.1023/B:BINV.0000034589.18347.d3).

422 Vilà M., Espinar J.L., Hejda M., Hulme P.E., Jarosik V., Maron J.L., Pergl J., Schaffner U., Sun

423 Y., Pysek P. 2011. Ecological impacts of invasive alien plants: a meta-analysis of their 424 effects on species, communities and ecosystems. Ecology Letters 14:702-708.

$425 \quad$ (doi:10.1111/j.1461-0248.2011.01628.x).

426 Williams S.L., Smith, J.E. 2007. A global review of distribution, taxonomy and impacts of 427 introduced seaweeds. Annual Reviews of Ecology, Evolution and Systematics 38:327-359. 428 Zuur A.F., Ieno E.N., Walker. N., Saveliev A.A., Smith G.M. 2009. Mixed effects models and 429 extensions in ecology with R. Springer, New York. 
Table 1. Linear-mixed models assessing the effects of C. cylindracea, land-based- and sea-based cumulative human impacts on extant assemblages. A) percentage cover of encrusting algae, turfs and sessile invertebrates; B) total cover and species richness; Coefficients, standard errors $(S E)$ and $p$-values are reported for fixed effects, while variance $\left(\delta^{2}\right)$ and standard deviation $(S D)$ are reported for random effects. Analyses of encrusting algae, sessile invertebrates and total cover are on log-transformed data.

\begin{tabular}{|c|c|c|c|c|c|c|c|c|c|}
\hline \multicolumn{10}{|c|}{ A) Morphological groups } \\
\hline \multirow[b]{2}{*}{ Fixed effects } & \multicolumn{3}{|c|}{ Encrusting algae } & \multicolumn{3}{|c|}{ Algal turfs } & \multicolumn{3}{|c|}{ Sessile invertebrates } \\
\hline & Estimate & $S E$ & $P$ & Estimate & $S E$ & $P$ & Estimate & $S E$ & $P$ \\
\hline Intercept & 1.470 & 0.994 & 0.165 & 57.49 & 60.37 & 0.365 & 1.252 & 1.760 & 0.488 \\
\hline - Caulerpa $=-C$ & 0.464 & 0.876 & 0.598 & 44.24 & 32.35 & 0.174 & -1.298 & 1.801 & 0.473 \\
\hline Land-based score $=\mathrm{L}$ & -0.219 & 0.076 & 0.014 & 5.39 & 4.62 & 0.272 & -0.192 & 0.135 & 0.174 \\
\hline Sea-based score $=\mathrm{S}$ & -0.017 & 0.225 & 0.942 & -7.51 & 13.69 & 0.596 & -0.067 & 0.399 & 0.868 \\
\hline - C. x L & 0.049 & 0.067 & 0.471 & 2.27 & 2.47 & 0.361 & -0.255 & 0.138 & 0.068 \\
\hline - C. x S & -0.109 & 0.199 & 0.585 & -9.06 & 7.32 & 0.220 & 0.569 & 0.409 & 0.168 \\
\hline Random effects & $\delta^{2}$ & $S D \delta^{2}$ & & $S D$ & $\delta^{2}$ & & $S D$ & & \\
\hline Site & 0.044 & 0.209 & & 226.1 & 15.04 & & 0.106 & 0.326 & \\
\hline Residual & 0.139 & 0.373 & & 188.2 & 13.72 & & 0.587 & 0.766 & \\
\hline \multicolumn{10}{|c|}{ B) Community response variables } \\
\hline & \multicolumn{4}{|c|}{ Total cover } & \multicolumn{5}{|c|}{ Species richness } \\
\hline Fixed effects & Estimate & \multicolumn{2}{|c|}{$S E$} & $P$ & \multicolumn{2}{|c|}{ Estimate } & \multicolumn{3}{|l|}{$S E$} \\
\hline Intercept & 2.545 & \multicolumn{2}{|c|}{0.178} & 0.000 & \multicolumn{2}{|c|}{22.422} & 6.404 & \multicolumn{2}{|l|}{0.003} \\
\hline - Caulerpa $=-C$ & -0.146 & \multicolumn{2}{|c|}{0.170} & 0.392 & \multicolumn{2}{|c|}{0.395} & 6.815 & \multicolumn{2}{|l|}{0.954} \\
\hline Land-based score $=\mathrm{L}$ & -0.022 & \multicolumn{2}{|c|}{0.014} & 0.137 & \multicolumn{2}{|c|}{-2.333} & 0.490 & \multicolumn{2}{|l|}{0.000} \\
\hline Sea-based score $=\mathrm{S}$ & -0.124 & \multicolumn{2}{|c|}{0.040} & 0.009 & \multicolumn{2}{|c|}{-1.467} & 1.453 & \multicolumn{2}{|l|}{0.328} \\
\hline$-C . \times \mathrm{L}$ & -0.008 & \multicolumn{2}{|c|}{0.013} & 0.540 & \multicolumn{2}{|c|}{-0.249} & 0.521 & \multicolumn{2}{|l|}{0.634} \\
\hline$-C \cdot \times \mathrm{S}$ & 0.057 & 0.038 & & 0.143 & 0.4 & & 1.546 & 0.795 & \\
\hline Random effects & $\delta^{2}$ & $S D$ & & & & $\delta^{2}$ & $S D$ & & \\
\hline Site & 0.001 & 0.036 & & & 1.2 & & 1.135 & & \\
\hline Residual & 0.005 & 0.072 & & & & & 2.899 & & \\
\hline
\end{tabular}


Table 2. Linear-mixed models assessing the effects of C. cylindracea, land-based- and sea-based cumulative human impacts on recovering assemblages. A) percentage cover of encrusting algae, turfs and sessile invertebrates; B) total cover and species richness. Coefficients, standard errors (SE) and $p$-values are reported for fixed effects, while variance $\left(\delta^{2}\right)$ and standard deviation $(S D)$ are reported for random effects. Analyses of encrusting algae, sessile invertebrates and total cover are on log-transformed data.

\begin{tabular}{|c|c|c|c|c|c|c|c|c|c|}
\hline \multicolumn{10}{|l|}{ A) Morphological groups } \\
\hline \multirow[b]{2}{*}{ Fixed effects } & \multicolumn{3}{|c|}{ Encrusting algae } & \multicolumn{3}{|c|}{ Algal turfs } & \multicolumn{3}{|c|}{ Sessile invertebrates } \\
\hline & Estimate & $S E$ & $P$ & Estimate & $S E$ & $P$ & Estimate & $S E$ & $P$ \\
\hline Intercept & 1.971 & 1.234 & 0.140 & 91.61 & 57.59 & 0.143 & 0.805 & 0.597 & 0.201 \\
\hline - C. cylindracea $=-C$. & -0.657 & 0.867 & 0.451 & 2.23 & 36.37 & 0.951 & -0.649 & 0.567 & 0.256 \\
\hline Land-based score $=\mathrm{L}$ & -0.118 & 0.094 & 0.239 & 4.01 & 4.41 & 0.385 & -0.167 & 0.046 & 0.003 \\
\hline Sea-based score $=\mathrm{S}$ & -0.161 & 0.280 & 0.578 & -13.86 & 13.06 & 0.314 & -0.008 & 0.136 & 0.956 \\
\hline - C. x L & -0.136 & 0.066 & 0.044 & 7.23 & 2.78 & 0.010 & -0.060 & 0.043 & 0.171 \\
\hline - C. x S & 0.209 & 0.197 & 0.291 & -2.93 & 8.25 & 0.724 & 0.191 & 0.129 & 0.143 \\
\hline Random effects & $\delta^{2}$ & $S$ & & $\delta^{2}$ & $S D$ & & $\delta^{2}$ & $S D$ & \\
\hline Site & 0.083 & 0.2 & & 192.2 & 13.86 & & 0.014 & 0.119 & \\
\hline Residual & 0.136 & 0.3 & & 239.4 & 15.47 & & 0.058 & 0.241 & \\
\hline \multicolumn{10}{|c|}{ B) Community response variables } \\
\hline & \multicolumn{3}{|c|}{ Total cover } & \multicolumn{6}{|c|}{ Species richness } \\
\hline Fixed effects & Estimate & $S E$ & & $P$ & Estir & nate & $S E$ & $P$ & \\
\hline Intercept & 2.359 & 0.2 & & 0.000 & & 058 & 6.813 & 0.002 & \\
\hline - C. cylindracea $=-C$. & -0.108 & 0.2 & & 0.660 & & 329 & 4.330 & 0.444 & \\
\hline Land-based score $=\mathrm{L}$ & -0.029 & 0.0 & & 0.196 & & 187 & 0.521 & 0.002 & \\
\hline Sea-based score $=\mathrm{S}$ & -0.081 & 0.0 & & 0.221 & & 723 & 1.545 & 0.109 & \\
\hline - C. x L & 0.014 & 0.0 & & 0.460 & & 000 & 0.331 & 0.004 & \\
\hline - C. x S & 0.029 & 0.0 & & 0.604 & & 521 & 0.982 & 0.126 & \\
\hline Random effects & $\delta^{2}$ & $S$ & & & $\delta$ & $2^{2}$ & $S D$ & & \\
\hline Site & 0.003 & 0.0 & & & & 581 & 1.637 & & \\
\hline Residual & 0.011 & 0.1 & & & & 392 & 1.842 & & \\
\hline
\end{tabular}


432 Legend to figures

433 Fig. 1. Map of the study sites in the Mediterranean Sea. The numbering of sites (1 to 8) follows

434 an increasing gradient of land-based human impacts. 1: Capraia island $\left(43^{\circ} 00^{\prime} 52.85^{\prime \prime} \mathrm{N}\right.$; $9^{\circ} 49^{\prime}$

435 27.52" E); 2: Elba island (42॰ 48' 33.18" N; $10^{\circ} 08^{\prime} 26.13^{\prime \prime}$ E); 3: Plemmirio (3700' 26.22" N;

$\left.436 \quad 15^{\circ} 20^{\prime} 12.6^{\prime \prime} \mathrm{E}\right) ; 4$ : Vrsar (45 8' 58.96" N; $\left.13^{\circ} 35^{\prime} 28.38^{\prime \prime} \mathrm{E}\right)$; 5: Fortullino (43 25' 39.66" N;

$43710^{\circ} 23^{\prime} 41.04^{\prime \prime}$ E); 6: Rosignano Solvay (432 24' 07.25" N; 10²4' 47.44" E); 7: Quercianella

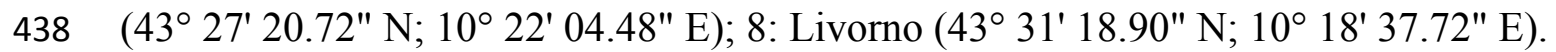

439 Fig. 2. Percentage cover of C. cylindracea in experimental plots at each site throughout the

440 study. Filled circle $=$ Extant assemblages + C. cylindracea $;$ Hollow circle $=$ Extant assemblages -

441 C. cylindracea ; Filled triangle $=$ Developing assemblages + C. cylindracea ; Hollow triangle $=$

442 Developing assemblages - C. cylindracea. Cumulative land-based (LBS) and sea-based (SBS)

443 and total human impact scores are reported for each study site.

444 Fig. 3. Extant assemblages. Relationship between land-based cumulative human impact score

445 and A) cover of encrusting algae (log scale) and B) species richness; C) relationship between

446 sea-based cumulative human impact score and total community cover (log scale). Jittering is

447 used to avoid overplotting.

448 Fig. 4. Recovering assemblages. Relationship between land-based cumulative human impact

449 score and A) cover of encrusting algae, B) cover of algal turfs and D) species richness, in plots

450 from which C. cylindracea was removed (black circles) or left untouched (grey circles). C)

451 relationship between land-based cumulative human impact score and cover of sessile

452 invertebrates (log scale). Jittering is used to avoid overplotting. 


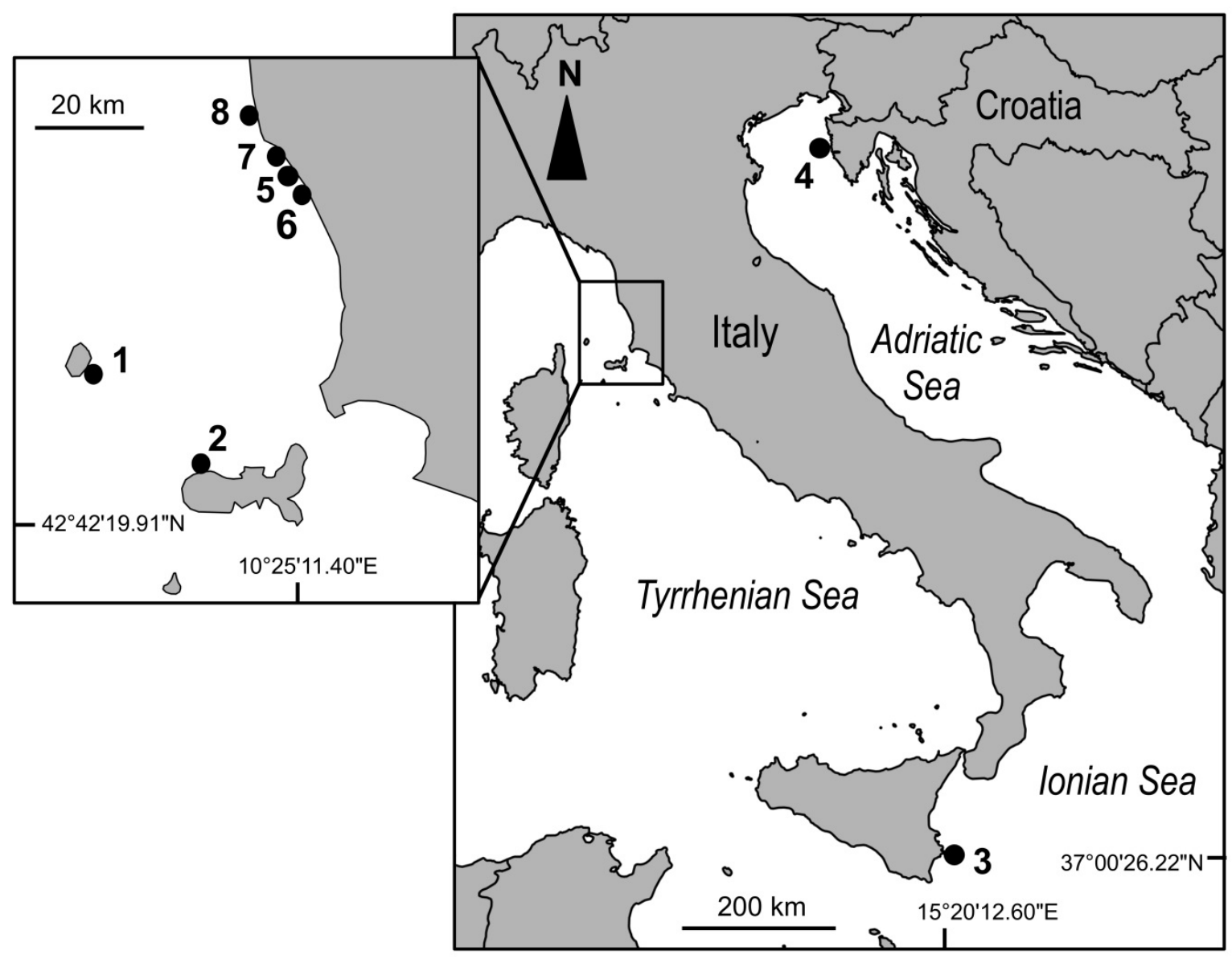



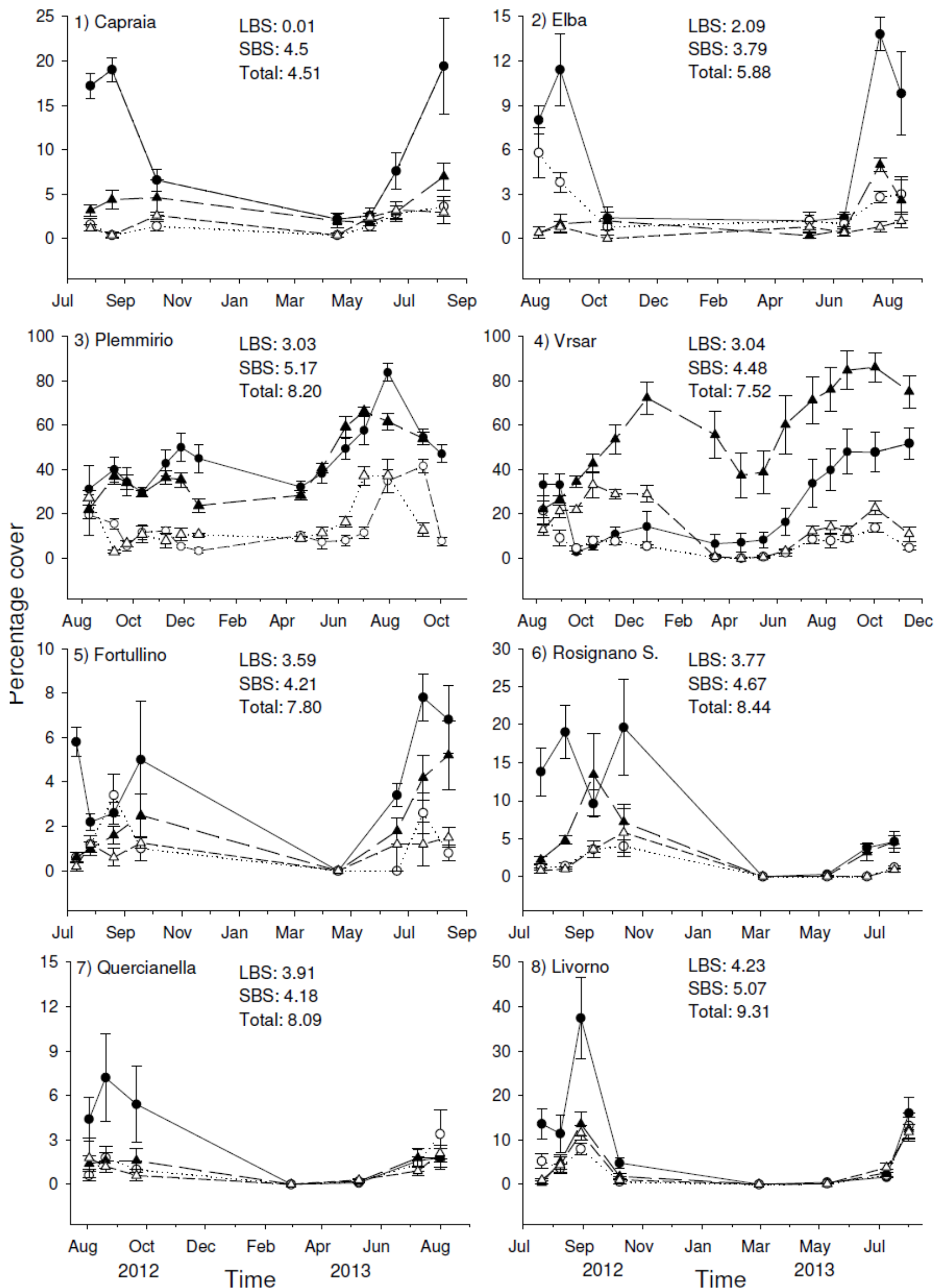

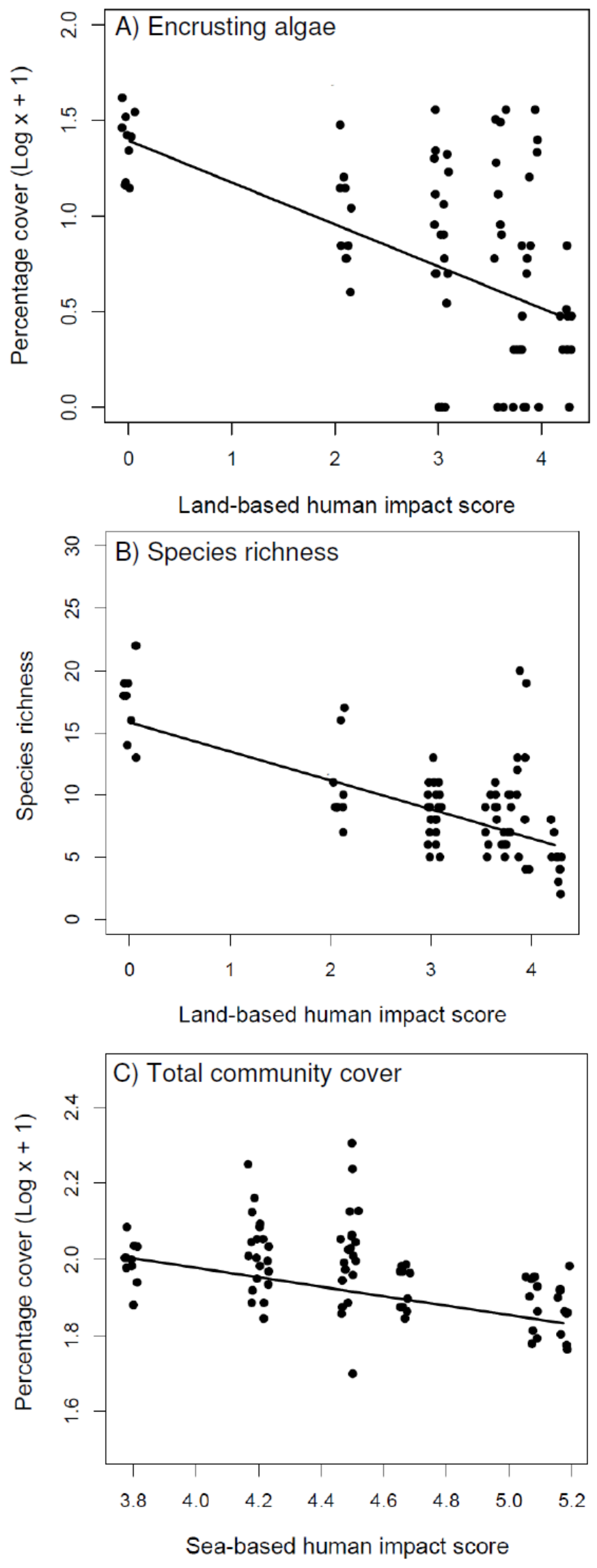

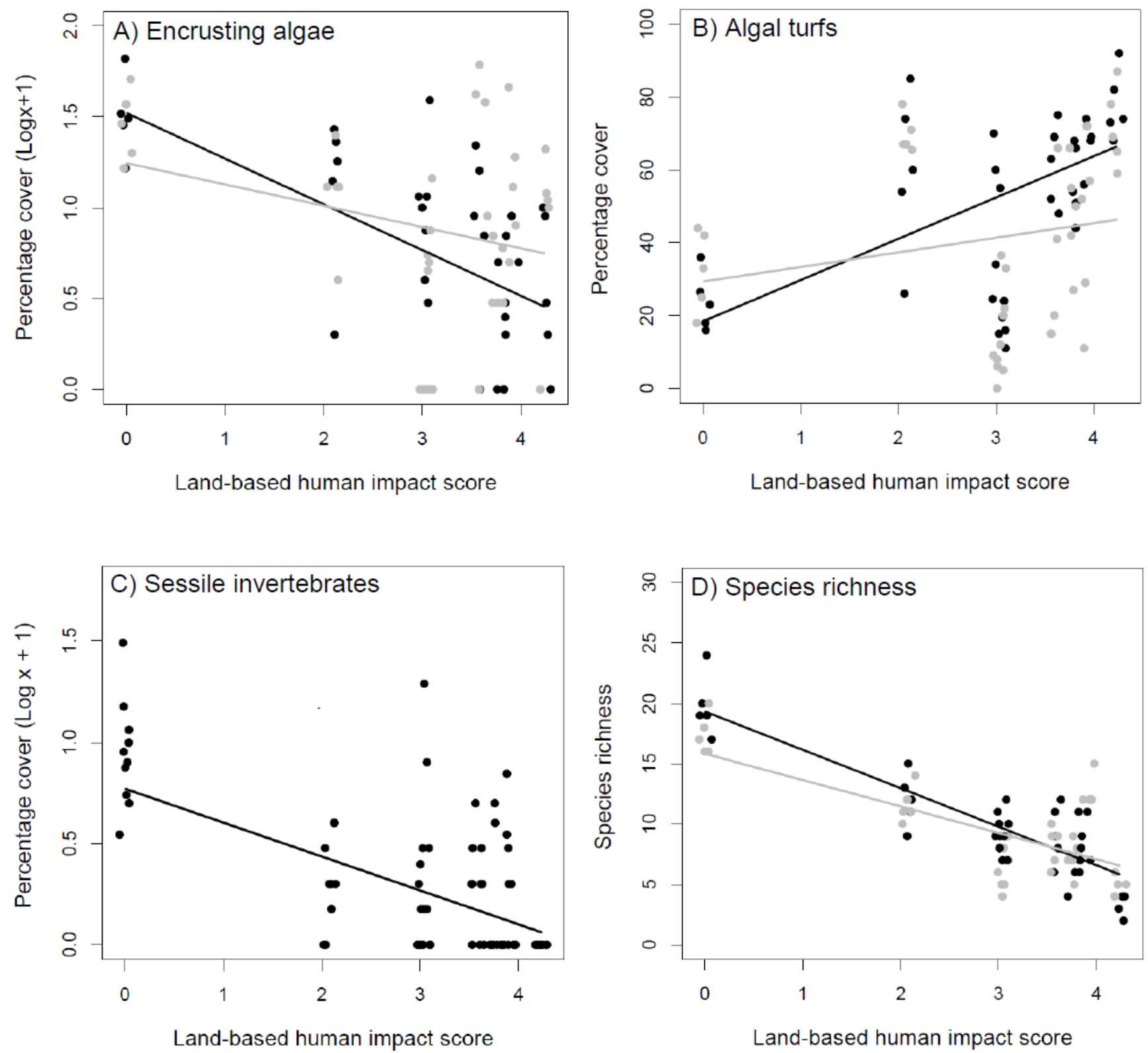